contains brain regions that deactivate when a cognitive task is being performed, was identified in the rs-fMRI data using independent component analysis.

Results The VPT group showed decreased functional connectivity (with the rest of the DMN) in the cingulate gyrus and increased connectivity in the left hippocampus compared to controls. In the whole sample (VPT and controls) MWF in the CC was negatively correlated with functional connectivity in the hippocampus and positively correlated with functional connectivity in the medial prefrontal cortex (mPFC). Moreover, the correlation between MWF and functional connectivity in the mPFC was stronger in controls than in VPT-born individuals. All analyses used a $p \leq 0.05$.

Conclusions The degree of myelination of the CC is associated with functional connectivity in the DMN, with altered MWFfunctional connectivity relationships displayed in adults born VPT in brain regions underlying important high-order cognitive processes.

\section{POOR MOTOR OUTCOME AT 2 YEARS OF AGE IS PREDICTED BY ELEVATED LEUKOCYTE COUNT IN INFANTS WITH PERINATAL ASPHYXIA}

doi:10.1136/archdischild-2012-302724.1060

${ }^{1} \mathrm{DU}$ Sweetman, ${ }^{2 \mathrm{P}}$ Lakatos, ${ }^{1,3,4} \mathrm{EJ}$ Molloy, ${ }^{2} \mathrm{~J}$ Kardasi, ${ }^{2} \mathrm{M}$ Bango, ${ }^{2} \mathrm{M}$ Szabó. 'Neonatology, The National Maternity Hospital, Dublin, Ireland; 'First Department of Paediatrics, Semme/weis University, Budapest, Hungary; ${ }^{3}$ Paediatrics, Royal College of Surgeons in Ireland; 'Neonatology, Our Lady's Children's Hospital Crumlin, Dublin, Ireland

Introduction An elevated white cell count in term newborns with neonatal encephalopathy (NE) has been associated with increased risk of mortality and neurological disability.

Aims To examine the associations between the white blood cell (WBC) indices of severely asphyxiated infants and mortality/neurodevelopmental outcome at 2 years.

Methods 69 infants with NE were randomized to normothermia or hypothermia as part of the TOBY trial. Serial WBC parameters, clinical outcome and 2-year developmental assessments were evaluated in 62 infants.

Results There were 46 survivors, 16 non-survivors. 43 infants received hypothermia therapy and the remainder $(n=19)$ kept normothermic. Elevated WBC count and Granulocyte count at 0-8 hours predicted mortality. ROC analysis favours Granulocyte count as the superior predictor of mortality. For each unit increase in WBC count the odds ratio of death increases by 1.076 for the normothermic group ( $\mathrm{p}=0.032$ ) but not for the hypothermic group ( $\mathrm{p}=0.290)$. High leukoycte counts at 20-28 hours (range 1-27 $\times 10^{9} / \mathrm{L}$ ) are associated with worsening motor scores $(p<0.0001)$ and with abnormal motor outcome.

Abstract 1060 Table 1 WBC count predictors of mortality in NE

\begin{tabular}{lccccc}
\hline Predictors of Mortality & Wald Statistic & Exp(B) & p-value & AUROC & p-value \\
\hline WBC count at 0-8 hours & 5.608 & 1.082 & 0.018 & 0.702 & 0.017 \\
Granulocyte count at 0-8 hours & 4.398 & 0.889 & 0.036 & 0.884 & 0.006 \\
\hline
\end{tabular}

Conclusion Elevated WBC counts increase the risk of mortality in the normothermic group but not in the hypothermic group. Raised leukocyte counts at 20-28 hours are associated with abnormal motor outcome at 2 years. WBC counts may play a future role in a biomarker panel helping to predict outcome following neonatal hypoxic-ischaemia.

\section{ARE VERY PRETERM BABIES WITH INTRAVENTRICULAR HAEMORRHAGE AT RISK FOR THYROID DYSFUNCTION?}

doi:10.1136/archdischild-2012-302724.1061
A Gupta, S Gupta. Department of Paediatrics, University Hospital of North Tees, Stockton-on-Tees, UK

Background and Aims Very preterm babies $(<32$ weeks $/<1500 \mathrm{~g})$ are prone for intraventricular haemorrhage (IVH) and are routinely screened in first and sixth week of life. There is however limited data whether presence of IVH in preterm babies affects endocrine functions.

We aimed to study correlation between intraventricular haemorrhage and thyroid function in very preterm babies.

\section{Methods}

- Preterm babies born $<32$ weeks $/<1500 \mathrm{~kg}$ and admitted to tertiary care neonatal unit between $1^{\text {st }}$ January 2009 and $31^{\text {st }}$ December 2010 to were identified.

- The results of the cranial scans and serum TSH were obtained from radiology records and newborn screening department respectively.

- The data was collated and analysed to study any co-relation between IVH and thyroid dysfunction. Data analysed using SPSS $®$ version 19.

\section{Results}

- During the study period 176 very preterm babies were admitted to the neonatal unit. Of these $27 \%(82 \%$ IVH) and $22.5 \%$ $\left(50 \%\right.$ IVH) had abnormal cranial ultrasound scans at $1^{\text {st }}$ and $6^{\text {th }}$ week respectively.

- The mean TSH for total cohort at $1^{\text {st }}$ and $6^{\text {th }}$ week was 1.25 and $1.51 \mathrm{mIU} / \mathrm{L}$ respectively. At $1^{\text {st }}$ and $6^{\text {th }}$ week, the mean TSH for babies with abnormal scans was 1.07 and $2.2 \mathrm{mIU} / \mathrm{L}$ respectively.

- There was significant difference in mean TSH values between babies with and without IVH in $1^{\text {st }}$ week (0.85 vs.1.37; $\mathrm{p}=.026$ ).

Conclusions From our data we conclude that presence of IVH adversely affects the thyroid function in very preterm babies. There is need for bigger studies in this area.

\section{IS THE USE OF PLACENTAL BIOPSY FEASIBLE FOR BIOMARKER ANALYSIS IN NEONATAL ENCEPHALOPATHY?}

doi:10.1136/archdischild-2012-302724.1062

${ }^{1,2} \mathrm{AM}$ Looney, ${ }^{2} \mathrm{LA}$ Kelly, ${ }^{1} \mathrm{BH}$ Walsh, 'GB Boylan, ${ }^{2} \mathrm{~S}$ Muttukrishna. 'Department of Paediatrics and Child Health; 'Department of Obstetrics and Gynaecology, University College Cork, Cork, Ireland

Background/Aim Encephalopathy following severe neonatal asphyxia is one of the leading causes of morbidity and mortality in term neonates. Therapeutic hypothermia has been shown to improve outcomes in moderate and severe encephalopathy if administered within six hours of birth. Rapid diagnosis of at-risk infants is therefore crucial. To-date, no effective early diagnostic biomarker has been established in blood, urine or CSF. Biomarkers in placental biopsies have been largely overlooked due to the perceived difficulty in obtaining and processing viable samples soon after birth. Our aim was to establish the feasibility of using placental biopsies for biomarker analysis in neonatal encephalopathy(NE).

Methods Placental biopsies were collected following elective caesarean sections(controls), stored according to 4 different protocols and snap frozen at 5 different time points after delivery. Immunohistochemical staining, total RNA and protein concentrations were used to analyse tissue degradation over time. Biopsies from infants with NA were also collected in a pilot study and our biopsy methodology applied. Potential biomarker expression levels were then determined using enzyme immune assays.

Results Our timeline study from 4 control placentas revealed that gene and protein expression results together with immunohistochemical findings showed limited deterioration on tissue viability up to 90 minutes after delivery. In 10 asphyxia placentas the expression profiles of four specific biomarkers(Activin-A, sFlt-1, IL-6 and 